\title{
Pengaruh Senam Lansia terhadap Penurunan Tekanan Darah pada Lansia
}

\author{
Eviyanti $^{1}$, Heny Noor Wijayanti ${ }^{2}$, Sitti Khadijah ${ }^{3}$ \\ Email : Yantievi869@gmail.com ${ }^{1}$, henywijayanti@respati.ac.id ${ }^{2}$,cha_midwife19@yahoo.com ${ }^{3}$ \\ Fakultas Ilmu Kesehatan, Universitas Respati Yogyakarta, Indonesia \\ J1. Raya Tajem Km 1.5 Maguwoharjo Depok Sleman DIY
}

\begin{abstract}
Abstrak
Penyakit terbanyak pada lansia adalah PTM antara lain hipertensi, artritis, stroke, PPOK dan DM. Hipertensi merupakan prevalensi tertinggi penyakit yang dialami lansia. Upaya yang dapat dilakukan penderita hipertensi untuk menurunkan tekanan darah dilakukan dengan dua jenis yaitu secara farmakologis dan non farmakologis, salah satu upaya secara nonfarmakologis yaitu latihan fisik (olahraga). Hasil stupen dari jumlah lansia sebanyak 128, yang hipertensi yaitu 67 lansia, dan lansia rutin melakukan senam lansia lima kali perminggu. Tujuan penelitian yaitu untuk mengetahui pengaruh senam lansia terhadap penurunan TD pada lansia di BPSTW unit Abiyoso Yogyakarta. Desain penelitian adalah kuantitatif eksperimental menggunakan pra eksperimental dengan rancangan one Group Pretest-Post Design. Subyek penelitian adalah lansia hipertensi yang tinggal di BPSTW Kab.Sleman Yogyakarta. Teknik sampling dengan Purposive Sampling. Analisis data menggunakan uji statistik dependen $t$ test, dan Wilcoxon. Hasil analisis TD sistolik sebelum dan setelah senam lansia dengan uji paired t-test nilai $p$ value sebesar 0,000 lebih kecil dari $0,05(p<0,05)$, dan TD diastolik dari uji Wilcoxon didapatkan nilai $p$ value sebesar 0,039 lebih kecil dari 0,05( $p<0,05)$ sehingga Ho ditolak. Bahwa terdapat pengaruh senam lansia terhadap penurunan TD sistolik dan diastolik pada lansia hipertensi di BPSTW unit Abiyoso Yogyakarta.
\end{abstract}

Kata Kunci: senam lansia; tekanan darah; lansia.

\begin{abstract}
Most diseases in the elderly are non-communicable diseases such hypertension, arthritis, stroke, Chronic Obstructive Pulmonary Disease (COPD) and DM. Hypertension is the highest prevalence of disease undergone by the elderly. Efforts to reduce blood pressure in hypertension sufferers can be made nonpharmacologically. One of the non-pharmacological efforts is physical exercise (sports). The result of a preliminary study in 128 elderly people indicated that 67 had hypertension, and the elderly routinely did elderly gym five times a week. Objective:To reveal the effects of elderly gym on reducing blood pressure in the elderly at BPSTW Yogyakarta of Abiyoso unit. This research employed preexperimental quantitative research using One Group Pretest-Post Design. The research subjects were elderly with hypertension who lived at BPSTW of Sleman Regency, Yogyakarta. Samples were taken using purposive sampling. Data were analyzed using dependent t-test and Wilcoxon. The results of systolic blood pressure analysis before and after the elderly gym using paired t-test indicated p-value of 0.000 which was less than $0.05(\mathrm{p}<0.05)$ and diastolic blood pressure using Wilcoxon test indicated $p$-value of 0.039 which was less than $0.05(\mathrm{p}<0.05)$, so that Ho was rejected. There is an effect of elderly gym on reducing systolic and diastolic blood pressure in elderly with hypertension at BPSTW Yogyakarta of Abiyoso unit.
\end{abstract}

Keywords: elderly gym; blood pressure; elderly. 
Jurnal Kebidanan Harapan Ibu Pekalongan

\section{Pendahuluan}

Kawasan Asia tenggara populasi lansia sebesar $8 \%$ atau sekitar 142 juta jiwa. ${ }^{1}$ Pada tahun 2050 diperkirakan populasi lansia meningkat 3 kali lipat dari tahun ini. Pada tahun 2000 jumlah lansia sekitar $5.300 .000(7,4 \%)$ dari total populasi sedangkan pada tahun 2010 jumlah lansia 24.000.000 $(9,77 \%)$ dari total populasi dan tahun 2020 diperkirakan jumlah lansia mencapai 28.800 .000 (11,34\%) dari total populasi. Sedangkan di Indonesia sendiri pada tahun 2020 di perkirakan jumlah lansia sekitar $80.000 .000 .^{(1)}$ Persentase penduduk lansia menurut kabupaten/kota di DIY pada tahun 2017 yang memiliki lansia terbanyak yaitu di kabupaten Gunung Kidul yaitu sebanyak 31,5\%, sedangkan di kabupaten Sleman (30,4\%), Bantul $(28,4 \%)$, dan Kota DIY (9,7\%). Menurut Profil Kesehatan Kab/Kota tahun 2017. ${ }^{(2)}$

Fungsi fisiologis pada saat bertambahnya umur mengalami penurunan akibat proses penuaan sehingga penyakit tidak menular banyak muncul pada lanjut usia. Penyakit terbanyak pada lanjut usia adalah Penyakit Tidak Menular (PTM) antara lain hipertensi, artritis, stroke, Penyakit Paru Obstruktif Kronik (PPOK) dan Diabetes Melitus (DM), dan hipertensi merupakan prevalensi tertinggi penyakit yang dialami lansia. ${ }^{(2)}$

Hipertensi atau penyakit tekanan darah tinggi merupakan suatu gangguan pada pembuluh darah sehingga mengakibatkan suplai oksigen dan nutrisi. ${ }^{(3)}$ Kondisi ini menyebabkan tekanan darah diarteri meningkat dan jantung harus bekerja lebih keras untuk memenuhi kebutuhan tersebut. Hipertensi merupakan penyakit yang banyak tidak menimbulkan gejala khas sehingga sering tidak terdiagnosis dalam waktu yang lama. Menurut WHO batas tekanan darah yang normal adalah 140/90mmHg. Ada beberapa faktor yang mempengaruhi hipertensi yaitu jenis kelamin, keturunan, merokok, obesitas, stress, alkohol, kurang olahraga dan usia. ${ }^{(3)}$

Masalah hipertensi di Indonesia cenderung meningkat, Riset Kesehatan Dasar (Riskesdas) tahun 2013 mendapatkan prevalensi hipertensi pada penduduk umur diatas 18 tahun di Indonesia cukup tinggi mencapai $26,5 \%$ dengan penduduk yang mengetahui dirinya menderita hipertensi hanya $7,2 \%$ dan yang minum obat anti hipertensi hanya $9,4 \%{ }^{(4)}$

Hipertensi dapat dihindari dengan menghindari faktor resiko dan mencegahnya dengan beberapa upaya yaitu menerapkan pola hidup sehat dengan melakukan aktifitas fisik secara teratur, kebutuhan tidur yang cukup, pikiran yang rileks dan santai, menghindari kafein, rokok, alcohol, dan stress, kemudian menerapkan pola makan yang sehat dengan menghindari atau mengurangi makanan yang mengandung lemak tinggi, tinggi kalori, berminyak, kolestrol, santan, garam berlebihan, dan penggunaan kadar gula tinggi. ${ }^{(3)}$

Upaya yang dapat dilakukan penderita hipertensi untuk menurunkan tekanan darah dilakukan dengan dua jenis yaitu secara farmakologis dan non farmakologis, terapi farmakologis dapat dilakukan dengan menggunakan obat antihipertensi, sedangkan terapi dengan nonfarmakologis dapat dilakukan dengan berbagai upaya yaitu: mengatasi obesitas dengan menurunkan berat badan berlebih, pemberian kalium dalam bentuk makanan, dengan konsumsi buah dan sayur, mengurangi asupan garam dan lemak jenuh, berhenti merokok, mengurangi konsumsi alcohol, menciptakan keadaan rileks, dan latihan fisik (olahraga) secara teratur. ${ }^{(5)}$ 
Jurnal Kebidanan Harapan Ibu Pekalongan

Jenis latihan fisik (olahraga) yang bisa dilakukan lansia antara lain adalah senam lansia. Senam lansia adalah serangkaian gerak nada yang teratur dan terarah serta terencana yang diikuti oleh orang lanjut usia dalam bentuk latihan fisik yang berpengaruh terhadap kemampuan fisik lansia. Aktifitas olahraga ini akan membantu tubuh agar tetap bugar dan tetap segar karena melatih tulang tetap kuat dan membantu menghilangkan radikal bebas yang berkeliaran dalam tubuh. ${ }^{(6)}$

Hasil dari studi pendahuluan pada tanggal 21 Januari 2019 di Balai Pelayanan Sosial Tresna Werdha Unit Abiyoso, Kabupaten Sleman Yogyakarta, setiap hari dari hari senin sampai dengan hari kamis rutin melaksanakan senam lansia kecuali tanggal merah, jumlah lansia sebanyak 128 lansia, dan pada tanggal 24 Maret 2019 peneliti melakukan studi pendahuluan ulang mengenai data lansia, dan jumlah lansia bertambah 1 orang dan 1 yang meninggal, sehingga jumlah lansia sebanyak 128 lansia yaitu (41) laki-laki dan (87) perempuan, dan yang mengalami hipertensi dengan umur $\geq 60$ tahun sebanyak 67 lansia, laki-laki sebanyak (45) lansia dan perempuan (22) lansia.

Dari latar belakang diatas maka peneliti tertatik untuk mengetahui pengaruh senam lansia terhadap penurunan tekanan darah pada lansia di Balai Pelayanan Sosial Tresna Werdha Unit Abiyoso.

\section{Metode Penelitian}

Jenis penelitian yaitu penelitian kuantitatif eksperimental menggunakan pra eksperimental dengan rancangan one Group PretestPost Design. Sampel pada penelitian yaitu lansia yang tinggal di BPSTW unit Abiyoso Sleman Yogyakarta dengan teknik pengambilan sampel dengan purposive sampling yang berdasarkan kriteria inklusi yaitu 1) lansia yang mengikurti senam lansia, 2) lansia yang siap menjadi responden dan kriteria eksklusi yaitu lansia yang duduk pada saat senam lansia. Teknik analisa data bivariate menggunakan uji statistik dependen $t$ test, jika data berdistribusi normal, dan jika data tidak berdistribusi normal, dilakukan pengujian dengan analisis Wilcoxon.

\section{Hasil dan Pembahasan}

\section{Analisa Univariat :}

Tabel 1. Distribusi Frekuensi karakteristik responden berdasarkan usia dan jenis kelamin lansia

\begin{tabular}{lll}
\hline $\begin{array}{l}\text { Karakteristik } \\
\text { Responden }\end{array}$ & $\begin{array}{l}\text { Frekuensi } \\
(\mathrm{n})\end{array}$ & $\begin{array}{l}\text { Persentase } \\
(\%)\end{array}$ \\
\hline Umur & & \\
$60-74$ tahun & 34 & $85 \%$ \\
$81-90$ tahun & 6 & $15 \%$ \\
\hline Jenis kelamin & & \\
Laki-laki & 9 & $22,5 \%$ \\
Perempuan & 31 & $77,5 \%$ \\
\hline Jumlah & 40 & $100 \%$ \\
\hline \multicolumn{2}{r}{ Berdasarkan tabel } & 1 diketahui
\end{tabular}

Karakteristik responden berdasarkan umur, sebagian besar responden adalah yang berusia 60-74 tahun sebanyak 34 orang $(85 \%)$, dan sebagian besar lansia dengan jenis kelamin perempuan sebanyak $31(77,5 \%)$.

Tabel 2. Distribusi Frekuensi senam lansia di BPSTW Yogyakarta unit Abiyoso.

\begin{tabular}{lll}
\hline $\begin{array}{l}\text { Rutin } \\
\text { senam }\end{array}$ & $\begin{array}{l}\text { Frekuensi } \\
(\mathrm{n})\end{array}$ & $\begin{array}{l}\text { Persentase } \\
(\%)\end{array}$ \\
\hline Rutin & 38 & $95,0 \%$ \\
Tidak rutin & 2 & $5 \%$ \\
\hline Jumlah & 40 & $100 \%$
\end{tabular}

Berdasarkan tabel 2 sebagian besar lansia yang rutin melakukan senam lansia yaitu sebanyak 38 orang (95\%). 
Jurnal Kebidanan Harapan Ibu Pekalongan

Tabel 3. Distribusi Frekuensi Gambaran Perubahan Tekanan Darah Lansia yang Mengalami Hipertensi Setelah

\begin{tabular}{lll}
\hline $\begin{array}{l}\text { Perubahan } \\
\text { TD }\end{array}$ & Sistolik & Diastolik \\
\hline Turun & 19 & 16 \\
Tidak turun & 21 & 24 \\
& & \\
\hline Jumlah & 40 & 40
\end{tabular}

Melakukan Senam Lansia

Berdasarkan tabel 3 diketahui bahwa gambaran perubahan tekanan darah lansia yang mengalami hipertensi setelah melakukan senam lansia mayoritas responden yang mengalami perubahan tekanan darah tidak turun yaitu tekanan darah sistolik sebanyak 21 responden, dan tekanan darah diastolik sebanyak 24 responden.

Tabel 4. Gambaran nilai rata-rata TD Sistolik Lansia Yang Mengalamami Hipertensi Sebelum Dan Sesudah Senam Lansia

\begin{tabular}{clll}
\hline $\begin{array}{c}\text { TD } \\
\text { Sistolik }\end{array}$ & $\begin{array}{l}\text { TD } \\
\text { Minimal } \\
(\mathrm{mmHg})\end{array}$ & $\begin{array}{l}\text { TD } \\
(\mathrm{mmHg})\end{array}$ & $\begin{array}{l}\text { Mean } \\
(\mathrm{mmHg})\end{array}$ \\
\hline Sebelum & 140 & 174 & 154,5 \\
Sesudah & 138 & 172 & 150,5
\end{tabular}

Berdasarkan tabel 4, diketahui bahwa nilai rata-rata tekanan darah sistolik sebelum senam adalah $154,5 \mathrm{mmHg}$ dan nilai rata-rata tekanan darah sistolik sesudah senam adalah 150,5 mmHg.

Tabel 5. Gambaran nilai rata-rata tekanan darah diastolik lansia sebelum dan sesudah senam lansia

\begin{tabular}{llll}
\hline TD & TD & TD & Mean \\
Diastolik & $\begin{array}{l}\text { Minimal } \\
(\mathrm{mmHg})\end{array}$ & $\begin{array}{l}\text { Maksimal } \\
(\mathrm{mmHg})\end{array}$ \\
& $(\mathrm{mmHg})$ \\
\hline Sebelum & 80 & 100 & 91,2 \\
Sesudah & 76 & 100 & 88,2
\end{tabular}

Berdasarkan tabel 5, diketahui bahwa nilai rata-rata tekanan darah diastolik sebelum senam adalah 91,2 $\mathrm{mmHg}$, dan nilai rata-rata tekanan darah diastolik sesudah senam adalah $89,2 \mathrm{mmHg}$.

\section{Analisis Bivariat :}

Tabel 6. Pengaruh Senam Lansia Terhadap Penurunan TD Sistolik Sebelum dan Sesudah Senam Lansia

\begin{tabular}{cccc}
\hline $\begin{array}{c}\text { Tekanan } \\
\text { Darah } \\
\text { Sistolik }\end{array}$ & Mean & $\begin{array}{c}\text { Selisih } \\
\text { Mean }\end{array}$ & $\begin{array}{c}P \\
\text { Value }\end{array}$ \\
Sebelum & $\begin{array}{r}154,2 \\
\mathrm{mmHg}\end{array}$ & & \\
\cline { 1 - 2 } Sesudah & $\begin{array}{c}150,2 \\
\mathrm{mmHg}\end{array}$ & & 0,000 \\
\hline
\end{tabular}

Hasil uji Wilcoxon menunjukkan bahwa nilai selisih dari kedua mean sebesar -4 Nilai $P$-value sebesar 0,000 Lebih kecil dari $0,05 \quad(p<0,05)$, sehingga Ho ditolak. Hal ini berarti bahwa ada pengaruh pelaksanaan senam lansia terhadap penurunan tekanan darah sistolik pada lansia di BPSTW unit Abiyoso Yogyakarta.

Tabel 7. Pengaruh Senam Lansia Terhadap Penurunan TD Diastolik Sebelum dan Sesudah Senam Lansia

\begin{tabular}{cccc}
\hline $\begin{array}{c}\text { Tekanan } \\
\text { Darah } \\
\text { Sistolik }\end{array}$ & Mean & $\begin{array}{c}\text { Selisih } \\
\text { Mean }\end{array}$ & $\begin{array}{c}P \\
\text { Value }\end{array}$ \\
Sebelum & 91,1 & & \\
& mmHg & & 0,039 \\
Sesudah & 88,9 & & \\
& $\mathrm{mmHg}$ & & \\
\hline
\end{tabular}

Hasil uji paired t-test menunjukkan selisi dari kedua mean sebesar -2 Nilai $p$ value sebesar 0,039 lebih kecil dari $0,05(p<0,05)$ sehingga Ho ditolak. Hal ini berarti bahwa ada pengaruh pelaksanaan senam lansia terhadap tekanan darah diastolik lansia di BPSTW unit Abiyoso Yogyakarta. 
Jurnal Kebidanan Harapan Ibu Pekalongan

Hasil analisis dengan uji paired ttest Nilai $p$ value sebesar 0,000 lebih kecil dari $0,05(p<0,05)$, sehingga Ho ditolak. Hal ini berarti bahwa ada pengaruh senam lansia terhadap penurunan tekanan darah sistolik lansia. Hasil penelitian ini mendukung penelitian yang dilakukan oleh Putu Dyah (2012), dengan hasil terdapat perubahan tekanan darah sistolik sebelum dan setelah dilakukan senam lansia dengan nilai $p$ value $=0,000$. Hal ini mengindikasikan bahwa terjadi penurunan nilai rata-rata tekanan darah sistolik setelah melakukan senam lansia. ${ }^{(2)}$

Penurunan rata-rata tekanan darah diastolik sesudah senam lansia. Hasil analisis didapatkan dari uji Wilcoxon didapatkan nilai $p$ value sebesar 0,039 lebih kecil dari $0,05(p<0,05)$ sehingga Ho ditolak. Hal ini berarti bahwa ada pengaruh pelaksanaan senam lansia terhadap penurunan tekanan darah diastolik lansia. Hasil penelitian ini juga mendukung penelitian yang dilakukan oleh Eti lestari, (2015), pada tekanan darah diastolik sebelum dan setelah diberikan senam lansia terhadap penurunan rata-rata tekanan darah diastolik sebanyak $12,50 \mathrm{mmHg}$ dari $91,25 \mathrm{mmHg}$ menjadi 78,75 $\mathrm{mmHg}$ dengan nilai $p$ value 0,000 . Hal ini mengindikasikan bahwa terjadi penurunan nilai rata-rata tekanan darah diastolik setelah dilakukan senam lansia. ${ }^{(7)}$

Senam lansia adalah olahraga ringan yang mudah digunakan dan tidak memberatkan lansia. Aktivitas olahraga akan membantu tubuh lansia agar tetap bugar dan tetap segar, karena senam lansia ini mampu membantu tulang tetap kuat, mendorong jantung bekerja secara optimal, dan membantu menghilangkan radikal bebas yang berkeliaran di dalam tubuh. ${ }^{(8)}$

Jenis senam untuk golongan lansia mempunyai manfaat besar karena dapat meningkatkan unsur-unsur kesegaran jasmani, yaitu sistem jantung dan pernapasan, kelenturan sendi dan kekuatan otot tertentu. Kesegaran jasmani yang baik bila jantung dan peredaran darah baik sehingga tubuh seluruhnya dapat menjalani fungsinya dalam waktu yang cukup lama. Senam lansia disamping memiliki dampak positif terhadap pengikatan fungsi organ tubuh juga berpengaruh pada peningkatan iminitas dalam tubuh manusia setelah latuhan teratur. ${ }^{(9)}$

Beberapa penelitian di atas yang berkenaan dengan pengaruh senam lansia terhadap penurunan tekanan darah pada lansia menyatakan bahwa terdapat pengaruh, dan hal tersebut sejalan dengan hasil penelitian yang dilakukan di BPSTW unit Abiyoso Kab.Sleman Yogyakarta. Sehingga dari pembahasan ini dapat dikatakan bahwa senam lansia bermanfaat untuk penurunan tekanan darah bagi lansia yang hipertensi.

\section{Kesimpulan}

Mayoritas lansia di Balai Pelayanan Sosial Tresna Werdha unit Abiyoso Sleman Yogyakarta rutin mengikuti senam lansia, pada hari pertama penelitian, lansia hipertensi yang mengikuti senam sebanyak 39 lansia, hari ke dua dan ke tiga sebanyak 40 lansia. Lansia yang rutin sebanyak 38 lansia, dengan mayoritas umur ratarata yaitu 60-70 tahun, sebanyak 27 lansia.

Nilai rata-rata tekanan darah sistolik sebelum senam adalah 154,2 $\mathrm{mmHg}$, dan tekanan darah diastolik sebelum senam adalah $91,1 \mathrm{mmHg}$. Nilai rata-rata tekanan darah sistolik setelah melakukan senam lansia adalah 150,2 $\mathrm{mmHg}$, dan tekanan darah diastolik setelah melakukan senam lansia adalah $88,9 \mathrm{mmHg}$.

Terdapat pengaruh senam lansia terhadap penurunan tekanan darah sistolik dan diastolik pada lansia 
Jurnal Kebidanan Harapan Ibu Pekalongan

hipertensi di Balai Pelayanan Sosial Tresna Werdha unit Abiyoso Yogyakarta.

Diharapkan dengan adanya hasil penelitian ini yang menunjukkan bahwa ada pengaruh senam lansia terhadap penurunan tekanan darah pada lansia hipertensi, lansia baik di dalam ataupun diluar Balai Pelayanan Sosial Tresna Werdha Yogyakarta untuk bersemangat dan selalu mengikuti senam lansia secara rutin, baik yang hipertensi maupun yang tidak, untuk mencegah terjadinya hipertensi.

\section{Daftar Pustaka}

[1] Kemenkes RI. Gambaran Kesehatan Lanjut Usia di Indonesia. Buletin Jendela: Jakarta, 2013.

[2] Putu. Dyah. Pengaruh Senam Lansia Terhadap Tekanan Darah Lansia, 2012.

[3] "Hipertensi di Desa Tumaratas 2 Kec. Langowan Barat Kab.Binahasa". Skripsi. Fakultas Kedokteran Universitas Sam Ratulangi.

[4] Tilong AD. Waspada PenyakitPenyakit Mematikan Tanpa Gejalah Menyolok. Yogyakarta: Buku Biru, 2014.

[5] Badan Pusat Statistik. Infodatin Pusat Data Informasi

Kementerian Kesehatan RI: Situasi Lanjut Usia di Indonesia, 2015. [Online]. 02 Desember 2018 dari http://www.depkes.go.id/resource s/download/pusdatin/versi/index. pdf.

[6] Widyanto dkk. Trend Disease (Trend Penyakit Saat Ini). Jakarta: Trans Info Media, 2013.
[7] Widianti dan Atika. Senam Kesehatan. Yogyakarta: Nuha Medika, 2010.

[8] Eti, L. Pengaruh senam lansia terhadap tekanan darah pada lansia hipertensi di Puskesmas Kalijambe Sragen. Skripsi. Stikes Kususma Husada, 2015.

[9] Depkes RI. Riset Kesehatan Dasar. Jakarta. Penelitian dan Pengembangan Kesehatan Kementrian Kesehatan RI, 2013.

[10] Effendi. Keperawatan dan Komunitas Teori dan Praktik Dalam Keperawatan. Jakarta: Salemba Medika, 2009. 